\title{
Using the Hardware-in-the-Loop concept for energetic evaluation of heat generators
}

\author{
Martin Knorr $^{1}{ }^{*}$, Joachim Seifert ${ }^{1}$, Lars Schinke ${ }^{1}$, Maximilian Beyer ${ }^{1}$, Philipp Mehrfeld $^{2}$ and Markus Nürenberg $^{2}$ \\ ${ }^{1}$ Technical University of Dresden, Institute of Power Engineering, 01062 Dresden, Germany \\ ${ }^{2}$ RWTH Aachen University, E.ON Energy Research Center, Institute for Energy Efficient Buildings and Indoor Climate, 52074 Aachen, \\ Germany
}

\begin{abstract}
Currently available energetic evaluation methods for heat pump and micro-CHP systems lead to results which partly deviate strongly from field measurements. A new evaluation method based on the Hardware-in-the-Loop concept was therefore developed and tested in a research project. The method employs representative days. A procedure for determining the representative days is presented. The functionality of the concept could be proven in a round robin test and the energetic key figures can be confirmed by values from field measurements values.
\end{abstract}

\section{Introduction}

The evaluation of heat generation systems in the building sector is important for an objective energetic, ecological and economic comparison of competing heat generation concepts. At the same time heat pumps and micro-CHP systems are becoming increasingly important in the context of changing energy supply structures. Related to these systems the results of field tests show not negligible deviations regarding heat pump's seasonal coefficient of performance (SCOP) compared to values determined according to state-of-the-art standards and directives, which are based on static methods and simplified dynamic measurements (see [1]). One reason for this is the insufficient representation of real boundary conditions in the evaluation and calculation procedures. In order to arrive at practical values, a valuation procedure based on Hardware-in-the-Loop methodology (HiL) is developed in a joint research project of the TU Dresden, the RWTH Aachen University and the University of Stuttgart. The project was financially supported by the German Federal Ministry for Economic Affairs and Energy (BMWi) under the code 03ET1211 A-C.

This article presents main results of the completed research project. First, the basic approach is documented. In a second step, selected results are presented. Finally, a proposal for an evaluation procedure derived from the results is explained.

\section{Existing energetic evaluation methods}

The Coefficient of Performance (CoP) is used to characterise the momentary efficiency of heat pumps. For electrically driven heat pumps, which were also the focus of the project, this is calculated according to
Equation 1 via the quotient of the thermal and electrical power at a given point in time.

$$
\operatorname{CoP}=\frac{\dot{Q}_{\mathrm{th}}}{P_{\mathrm{el}}}
$$

In addition to this momentary value, the efficiency over certain periods of time, which results from the integration of the thermal and electrical power and thus from the quotient of energy values, can be expressed (see Equation 2 ). For the duration of one year, this key figure is the annual or seasonal performance factor SCOP.

$$
S C O P=\frac{\int \dot{Q}_{\mathrm{th}}}{\int P_{\mathrm{el}}}=\frac{Q_{\mathrm{th}}}{W_{\mathrm{el}}}
$$

Current normative methods such as DIN EN 14825 [2] or german guideline VDI 4650 [3] provide methods for calculating of SCOP. The calculation methods are based on CoP values, which are determined in quasi-stationary operating points according to DIN EN 14511 [4]. The thermal power output represents the heat transferred in the condenser as well as any heat provided by supporting heaters. In the electrical balance the compressor power and, if necessary, the current power requirement of a heating rod as well as some other consumers in the system are included. In addition, the current energy label for heat pump systems according to the ErP Directive is based on DIN EN 14825 [2].

For cogeneration systems, the overall efficiency is calculated from the thermal and electrical efficiency according to Equation 3. Since two forms of energy are combined in the overall efficiency, the electrical partial

*orresponding author: martin.knorr@tu-dresden.de 
efficiency can also be weighted with primary energy factors. However, these factors are influenced by political constraints and are therefore only conditionally suitable for a neutral technical description.

$$
\eta_{\text {tot }}=\frac{Q_{\mathrm{H}}}{Q_{\text {end }}}+\frac{W_{\text {el }}}{Q_{\text {end }}}
$$

The heat output results by measuring the flow and return temperature as well as mass flow at the device from the calorific balance according to Equation 4. For gas powered CHP units the end energy is determined by the energy stored in the fuel with reference to the lower heating value (see Equation 5).

$$
\begin{gathered}
Q_{\mathrm{H}}=\int_{0}^{\tau_{\mathrm{B}}}\left(\dot{m}_{\mathrm{W}} \cdot c_{\mathrm{p}, \mathrm{W}} \cdot\left(\vartheta_{\mathrm{fl}}-\vartheta_{\mathrm{re}}\right)\right) d \tau \\
Q_{\text {end }}=\int_{0}^{\tau_{\mathrm{B}}}\left(\dot{m}_{\text {fuel }} \cdot H_{\mathrm{i}}\right) d \tau
\end{gathered}
$$

A measurement method for determining the overall efficiency is described in the standard DIN 4709 [5] $^{\mathrm{a}}$. The test program contains a load profile which maps different partial load conditions over a period of 24 hours.

\section{Research methodology}

In order to consider realistic boundary conditions, an evaluation procedure based on results obtained by measurements on the HiL test stand shall be developed. In principle, the HiL concept shown in Figure 1 is followed.

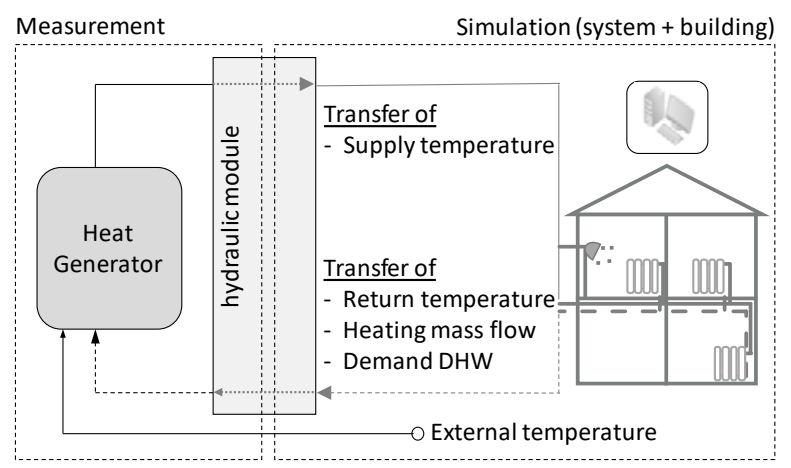

Fig. 1. Data transfer of the HiL test bench

In detail, within the emulation, the supply temperature is transferred to the heating system of the simulation on the one hand, on the other hand the simulation provides the mass flow and the return temperature of the heating system, which result from the simulated system dynamics. The demand for domestic hot water (DHW) is also transferred to the hydraulic module on the basis of the tap profile stored in the simulation. Suitable interfaces must

\footnotetext{
${ }^{a}$ DIN 4709 has been withdrawn and the use of the standard DIN EN 50465 [6] is recommended. However, since DIN EN 50465
}

be available for the transfer of these variables. In addition, the technical components of the test bench must be able to adjust the variables obtained from the simulation as quickly as possible.

To meet these requirements, a design for the test bench was implemented in accordance with Figure 2. At the test bench, the heating return temperature, heating volume flow and DHW volume flow are conditioned via a hydraulic module. The required return flow temperature is provided by a mixture of cold water from a recooling system and hot water from the output of the storage through a three-way valve. The actual value of the heating mass flow is adapted to the setpoint value by adjusting a throttle valve. Similarly, the DHW volume flow is controlled via a throttle valve. For test objects with an outdoor unit, a climatic chamber is also used which emulates the outside air temperature and humidity.

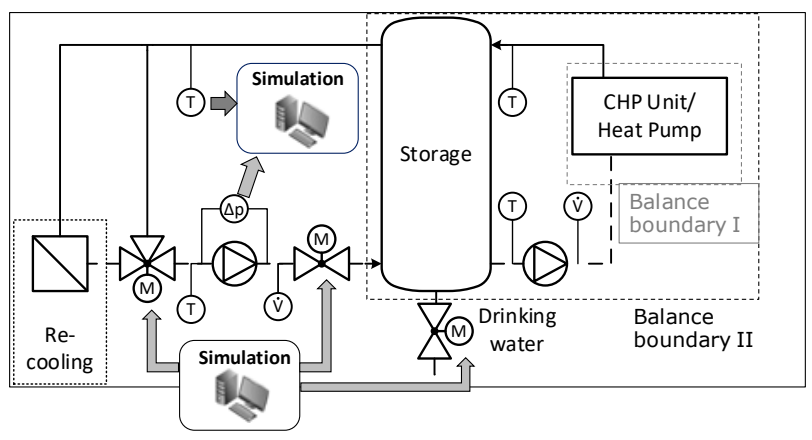

Fig. 2. Hydraulic circuit of the HiL-test bench

An essential criterion for the configuration of the HiL experiment is the definition of the system boundary between simulation and measurement, which also influences the energetic balancing. According to Figure 2, on the one side the boundary can encompass only the heat generator itself (Balance boundary I) or on the other side also include the storage in the sense of a system evaluation in the measurement (Balance boundary II). It is to be regarded as advantageous for Balance boundary I that the device configuration is not predetermined by the structure of the test facility and a simple variation, e.g. of the storage size, is possible in the simulation. The main advantage of Balance boundary II, on the other hand, is that the internal device control of the generator can directly access the sensors in the storages and thus no sensor manipulation is required and there is no dependency on a numerical storage model. Since in particular interventions in the system control are to be avoided as far as possible, the evaluation is carried out on the basis of Balance boundary II (system concept).

A system is tested in accordance with the time control schematically shown in Figure 3. On the simulation side, the concept includes the preconditioning of the thermal mass in the building by starting the calculation with sufficient settling time before the first representative day (see Section 4). At the same time, heat generators and storage tanks are thermally preconditioned to the starting

does not include a new dynamic test method for determining the degree of efficiency, the procedure according to DIN 4709 is used for comparative considerations. 
conditions of the first day. After a coupling during a representative day the building is further calculated in the simulation and at the same time any necessary conditioning measures are carried out at the test bench. The test is completed after the coupling for the last representative day has been completed.

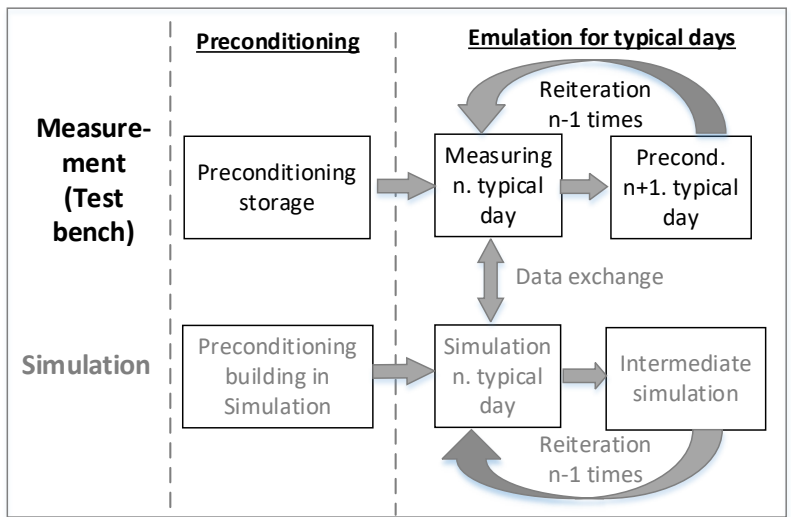

Fig. 3. Procedure of HiL-test method

The simulation of time periods between the typical days is necessary, because due to the high thermal mass of buildings, the effects of the so-called "energy shifting" must be considered or minimized when using representative days. By "energy shifting" is meant the influence of initial and final conditions on the building's thermal storages (e.g. walls and furniture) and technical systems (e.g. buffer storages) on the energy requirements of a given period of time. For example, if a representative day for a cold winter period directly follows a representative day for a transitional period, the energy requirement for this cold winter day is estimated to be too low due to the still high temperature level in the walls.

With regard to the simulation, various programs were used, which all implement a coupled, dynamic building and system simulation. The TU Dresden uses the numerical simulation program Trnsys-TUD [7]. It is a comprehensively revised and extended program version of the commercial simulation program Trnsys [8]. The modelling language Modelica [9] is used by the RWTH Aachen and executed in the software environment Dymola [10]. The University of Stuttgart uses the simulation software Trnsys 17 [11]. This procedure can be used to prove whether the results can be reproduced by using different software.

As heat generators with a lower capacity were initially considered, the use of single-family houses or small multi-family houses as model buildings is required. The single-family house shown in Figure 4 was therefore chosen as the object of investigation, which has a heated floor area of $\mathrm{A}=158 \mathrm{~m}^{2}$ and is divided into two floors with saddle roof. The heating system is also reproduced in the model and is designed as a two-pipe heating system. In addition to the energy demand for the heating the heat generator must also cover the energy demand for domestic hot water. For this purpose, the standardised tap profile according to DIN EN 16147 [12] is specified in size L. This profile specifies a tapped hot water volume of 2001 per day and is therefore representative of the size and type of building.

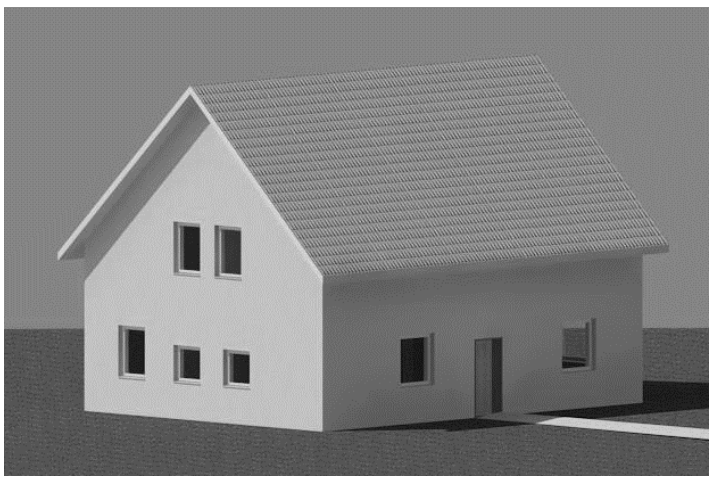

Fig. 4. View of the building model

\section{Determination of representative days}

Since a year-round experimental test is excluded due to the high time expenditure and the consistent test bench occupancy, an approach is pursued to map the representation period from one year to a few test days. The aim is to reproduce a year through meteorologically representative days. This ensures that the dynamics typical for a day and thus realistic for the heat generator are retained. In [13] various methods for determining representative days using numerical simulations were investigated. In this analysis the results of annual simulations with a heat pump system were compared with those of a simulation of only a few test days.

The resulting method for determining the test days is the guaranteed converging optimization method kmedoids clustering, since it led to the smallest deviations in the investigation with regard to the extrapolated SCOP and the SCOP from the annual simulations. At this extrapolation means that thermal and electrical energies or energies bound in the fuel during the test days are detected and extrapolated to one year.

In the k-medoids clustering method days of a year are divided into a number of clusters or groups. Each cluster center is representative for a certain number of days in the year. The squared error is calculated between each day and each cluster center according to Equation 6. The reference to the respective variance of the weather size results in a normalization. Each day is assigned to the cluster center for which it has the smallest squared error. In order to evaluate not only daily mean values but also to take into account the course of the weather size over the course of the day, the squared errors are formed separately for each data point on the day (hourly values).

$$
E S=\min \sum_{i=1}^{l} \sqrt{\sum_{j=1}^{m}\left(\sum_{k=1}^{n}\left(\frac{\left(x_{j, k}-\mu_{i, j, k}\right) \cdot f_{j}}{x_{j, \max }-x_{i, \min }}\right)^{2}\right)}
$$

The weighting factors $f_{j}$ are used in the procedure to take into account the specific influence of the respective weather size on the energy demand. A sensitivity analysis was performed in [13] and weighting factors were 
determined according to Table 1. The listed weather characteristics were varied within reasonable limits and the influence on the heat pump efficiency was quantified by annual simulations.

Table 1. Weighting factors for weather characteristics

\begin{tabular}{|c|c|c|}
\hline \multicolumn{3}{|c|}{ Weather characteristic } \\
\hline $\begin{array}{c}\text { External } \\
\text { temperature }\end{array}$ & $\begin{array}{c}\text { Direct solar } \\
\text { radiation }\end{array}$ & $\begin{array}{c}\text { Diffuse solar } \\
\text { radiation }\end{array}$ \\
\hline 0.90 & 0.03 & 0.07 \\
\hline
\end{tabular}

The measured energy values of the typical days can be multiplied by the number of days allocated to the cluster $i$ and then summed up so that at the end two extrapolated annual energy values are divided in order to obtain for CHP-units the annual utilisation factor (see Equation 7) or for heat pumps the annual performance factor (see Equation 8).

$$
\begin{gathered}
\eta_{\mathrm{tot}}=\frac{\sum_{i=1}^{l}\left[a_{i} \cdot\left(Q_{\mathrm{th}, i}+W_{\mathrm{el}, i}\right)\right]}{\sum_{i=1}^{l}\left(a_{i} \cdot Q_{\mathrm{fuel}, i}\right)} \\
S C O P_{\mathrm{tot}}=\frac{\sum_{i=1}^{l}\left[a_{i} \cdot Q_{\mathrm{th}, i}\right]}{\sum_{i=1}^{l}\left(a_{i} \cdot W_{\mathrm{el}, i}\right)}
\end{gathered}
$$

As an example Table 2 shows the typical days gained using the procedure from the German test reference year 04 , region 4 [14]. The number of 4 representative days proved to be a good compromise between measuring effort and accuracy in simulation studies. However, this number is not fixed and can be adapted to the respective requirements.

Table 2. Representative days using weather data from TRY04

\begin{tabular}{|c|c|c|c|c|c|}
\hline $\mathbf{i}$ & Date & $\begin{array}{c}\vartheta_{\mathrm{e}} \\
\text { in }^{\circ} \mathbf{C}\end{array}$ & $\begin{array}{c}\boldsymbol{I}_{\text {direct }} \\
\text { in } \mathbf{W} / \mathbf{m}^{\mathbf{2}}\end{array}$ & $\begin{array}{c}\boldsymbol{I}_{\text {diffuse }} \\
\text { in } \mathbf{W} / \mathbf{m}^{\mathbf{2}}\end{array}$ & $\boldsymbol{a}_{\mathbf{i}}$ \\
\hline 1 & 11. Jan. & 6.2 & 1 & 19 & 97 \\
\hline 2 & 27. Feb. & 0.6 & 0 & 22 & 103 \\
\hline 3 & 01. Jun. & 18.3 & 189 & 98 & 73 \\
\hline 4 & 30. Aug. & 13.8 & 24 & 98 & 92 \\
\hline
\end{tabular}

\section{Results}

Within the framework of the research project, the individual project partners analysed different types of heat generators in accordance with Table 3 . In order to validate the measurement results obtained, a round robin test was carried out, in which a device measured at one institute was tested again at another institute. The system configuration and the device settings were left unchanged. Differences arose with regard to the test rigs and the coupled simulation software. For the purpose of validation, on the one hand, the energetic characteristics for the individual representative days were compared and on the other hand, qualitative curves of selected measured quantities were also compared.
Table 3. Types of generators considered in the HiL experiments and simulation software used

\begin{tabular}{|l|c|l|}
\hline $\begin{array}{l}\text { Heat } \\
\text { Generator }\end{array}$ & Capacity & $\begin{array}{l}\text { Simulation } \\
\text { Software }\end{array}$ \\
\hline $\begin{array}{l}\text { Micro-CHP } \\
\text { Stirling) }\end{array}$ & $\begin{array}{c}\text { Stirling: } \dot{\mathrm{Q}}_{\mathrm{th}, \mathrm{N}}=6 \mathrm{~kW} \\
\mathrm{P}_{\mathrm{el}, \mathrm{N}}=1 \mathrm{~kW}\end{array}$ & $\begin{array}{l}\text { Trnsys- } \\
\text { TUD }\end{array}$ \\
\hline $\begin{array}{l}\text { Ground source } \\
\text { Heat pump }\end{array}$ & $\dot{\mathrm{Q}}_{\mathrm{th}, \mathrm{N}}=13.3 \mathrm{~kW}$ & Dymola \\
\hline $\begin{array}{l}\text { Air source } \\
\text { Heat pump }\end{array}$ & $\dot{\mathrm{Q}}_{\mathrm{el}, \mathrm{N}, \mathrm{N}}=4.0 \mathrm{~kW}(\mathrm{~W} 10 \mathrm{~W} 55)$ & Modelica \\
\hline
\end{tabular}

Figure 5 shows the basic functionality of the test bench as an example for a winter day. The heating volume flow shows the characteristic load peaks in the morning and evening hours, which are caused by the variable specification of the room set temperatures. The setpoint and actual value comparison for the morning and evening hours shows that a high control quality can be achieved by the test bench.

Figure 6 documents the results of the emulation tests for the micro-CHP unit. On typical days 1 and 2, the heat for space heating dominates the total demand, while on typical days 3 and 4 almost totally the heat demand for DHW dominates. As a result, the load levels on typical days 3 and 4 are significantly below the values for typical days 1 and 2, which leads to low utilisation rates. However, since absolute energy values are included in the annual calculation, the annual utilisation rate is essentially determined by the results of typical days 1 and 2 .

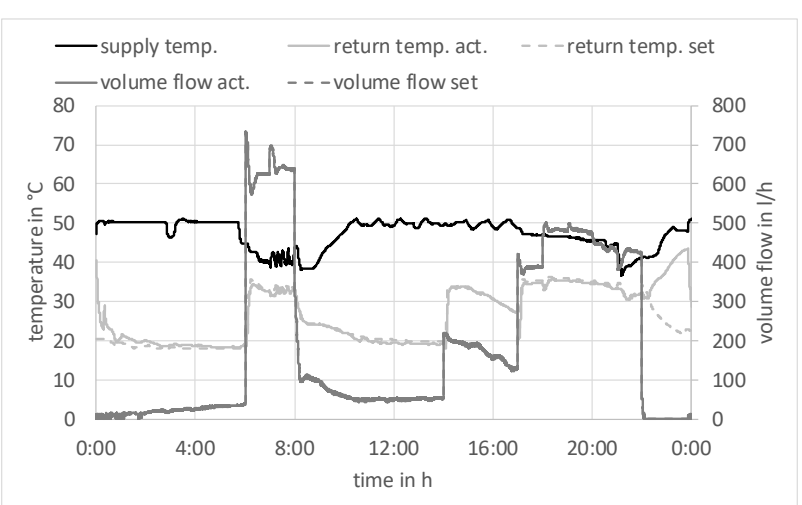

Fig. 5. Temperatures and volume flows for typical day 1 , micro-CHP

With regard to the round robin test, a good congruency of the specific annual efficiency can be achieved between the two test rigs as shown in Figure 6. The efficiency values for the individual type days also differ only slightly, with the relative deviation to the summer or transition dates being higher. The differences occurring between the absolute values of the energy demand are due to the use of different simulation programs (see Figure 7). 


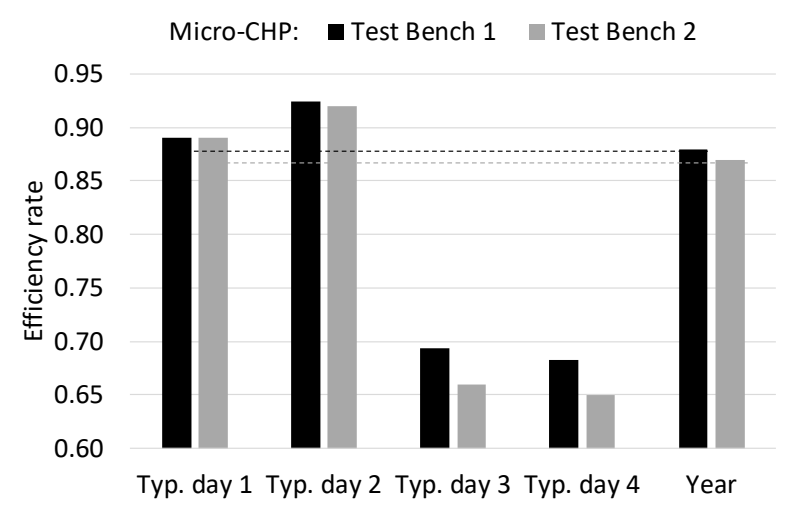

Fig. 6. Utilisation rates (annual utilisation rate represented by a dashed line), micro-CHP, results round robin test

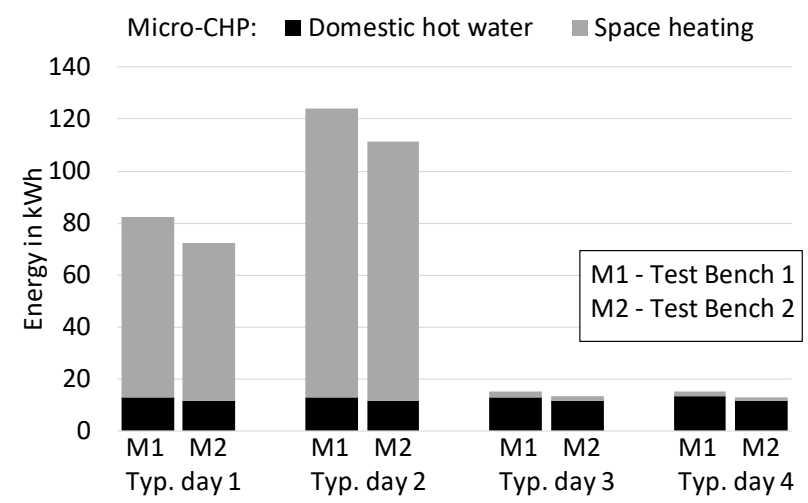

Fig. 7. Measured heat, micro-CHP, results round robin test

For the ground source heat pump (GSHP) Figure 8 and Figure 9 illustrate the energetic characteristic values determined within the round robin test. With regard to the level of the daily coefficients of performance, the tendency is confirmed analogous to the CHP unit that significantly higher coefficients of performance are determined with increasing load of the generator (typical days 1 and 2). The difference is even more significant than with the micro-CHP unit, as the heat pump reacts even more sensitively to the switching frequency and changing temperature conditions.

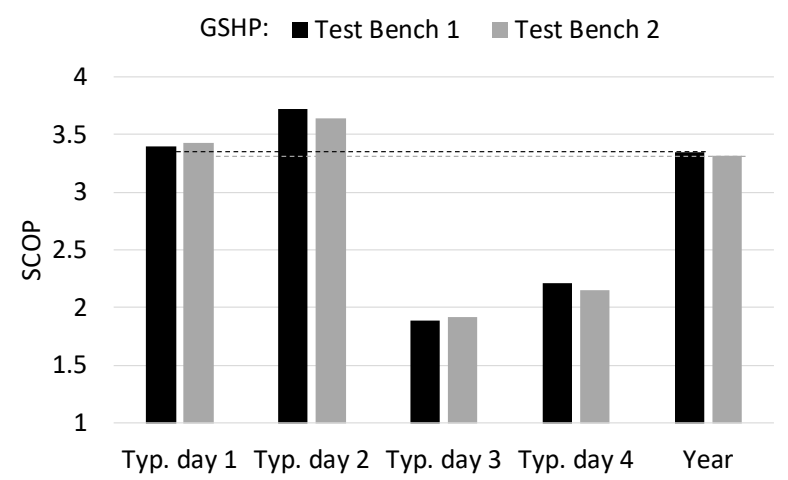

Fig. 8. SCOP (annual SCOP represented by a dashed line), GSHP, results round robin test
Overall, however, the calculated annual coefficient of performance is again significantly determined by the typical days 1 and 2 , so that the very low daily coefficients of performance with almost exclusive drinking water heating (typical days 3 and 4 ) are not so influential.

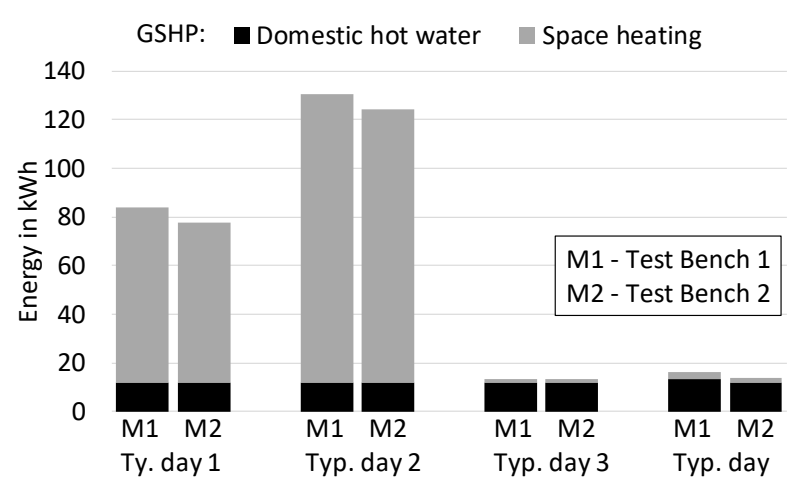

Fig. 9. Measured heat, GSHP, results round robin test

Figure 10 and 11 show the results of the round robin test with the air source heat pump (ASHP). Similar to the Micro CHP, the efficiencies of typical days 3 and 4 are lower than on typical days 1 and 2 due to the low heating demand. The comparison of the efficiency within the round robin test reveals a good correspondence of the annual SCOP values. Within the individual days, slight discrepancies are still recognizable. This applies in particular to typical days 3 and 4, where the demand for DHW predominates. One reason for this can be the different integration of the cold water into the respective test benches, which results in different cold water temperatures at the beginning of the tap. In addition, the significant influence of the climatic chamber on the conditioning of the outside air for the ASHP must also be mentioned. Here, for example, defrosting processes can lead to shifts in the energetic evaluation.

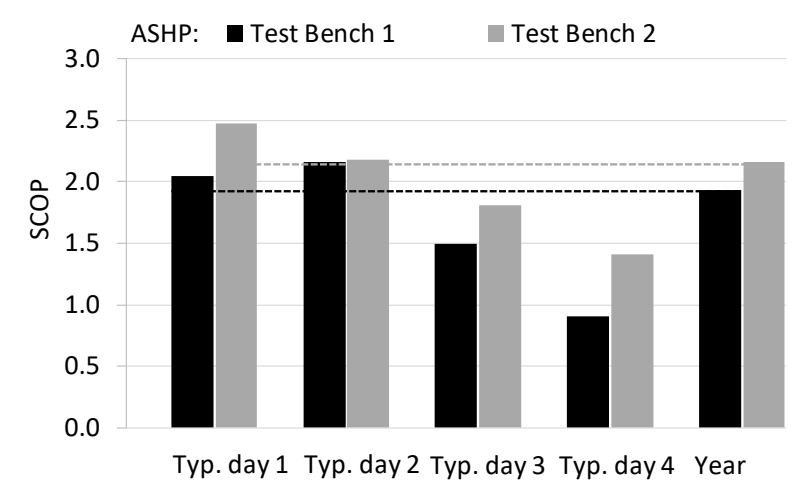

Fig. 10. SCOP (annual SCOP represented by a dashed line), ASHP, results round robin test 


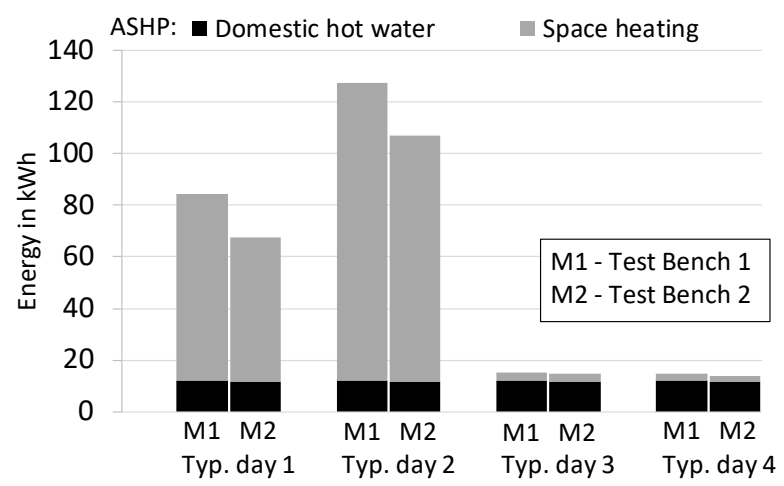

Fig. 11. Measured heat, ASHP, results round robin test

\section{Energetic evaluation method}

The described test results show that the chosen emulation approach is suitable for the energetic evaluation of heat pumps and micro-CHP units. Therefore, a test procedure with the sequence shown in Figure 12 is proposed. The procedure basically comprises the test bench side (Figure 12 above, black) and the simulation side (Figure 12 below, grey).

In preparation for the test, the generation system is first installed on the test bench by connecting it to the hydraulic module. The parameters of the system control must be set according to the building and the hydraulic connection. Outdoor temperature values have to be specified for the generator system in accordance with the typical days. This can be done by information technology manipulation via the respective communication protocol, by immersing the sensor in a thermostatic bath or by operation in the climatic chamber.

On the simulation side, the building model must be adapted to the maximum power of the generator system. For this purpose, the building is selected from a database, whereby the building heating load is used as the decisive selection criterion. The tap profile is selected in accordance with DIN EN 16147 [12] according to the size of the building.

The test begins with the preconditioning of the building and storage and is followed by the emulation of the typical days. As already explained in Section 3, a new preconditioning time is accomplished before each typical day. Once the tests have been completed, it is checked whether the tests were valid by comparing the energy expenditure with the target values and checking the success criteria for the DHW taps. The energy parameters are then used to calculate the key figures for evaluating the efficiency of the heat generation system (annual utilisation rate, annual performance factor).

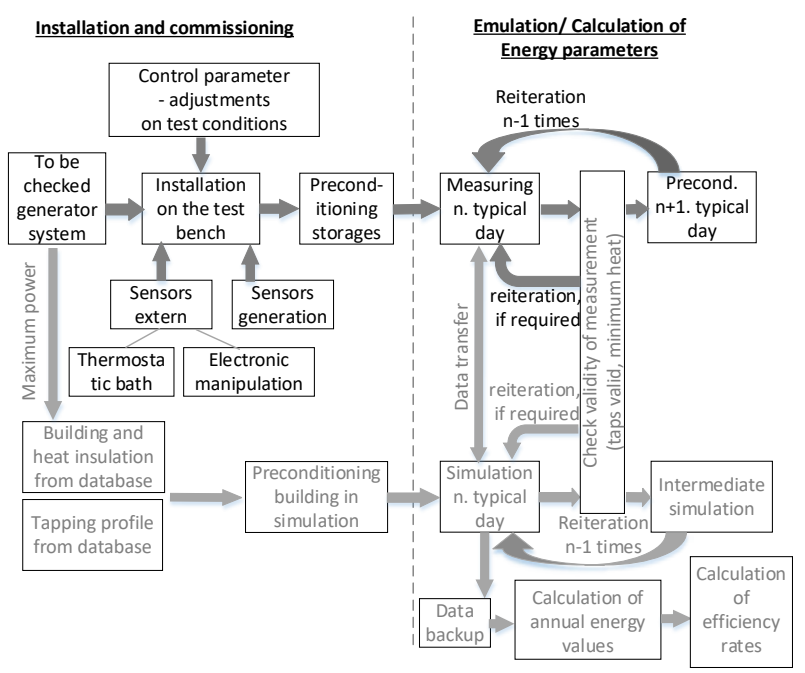

Fig. 12. Energetic evaluation of heat generators with HiLschematic sequence of the process

On the basis of the results for the ground source heat pump, the evaluation procedure with emulation can be classified in comparison to the results of existing procedures. For this purpose, the annual performance factor of the heat pump measured in the emulation test was calculated using the method according to VDI 4650 [3]. As Figure 13 shows, the SCOP determined in the HiLtests reflects well the order of magnitude determined in the field measurements. At this point, however, it should be noted that the balancing boundary according to VDI 4650 [3] refers to "Balance boundary I" (see Figure 3), whereas the HiL method is based on "Balance boundary II". Overall, it can be concluded that the new method provides a more realistic evaluation.

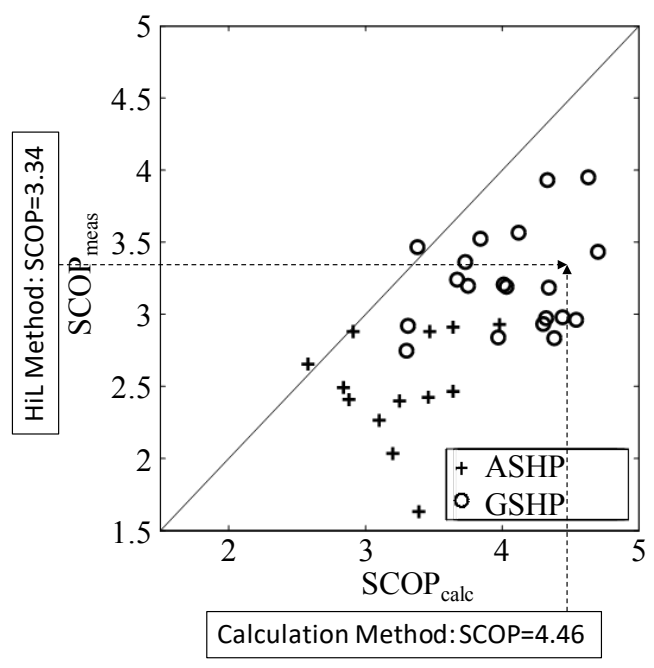

Fig. 13. Field measurements against calculations of SCOP according to VDI 4650 [3] for different heat pump systems in existing buildings according to [1] - Classification Results HiL method 


\section{Conclusions}

This paper presents the results of a research project for the development of an evaluation procedure for selected heat generators. The described procedure is based on a coupling of numerical building and system simulation as well as measurement analysis. This Hardware-in-theLoop method combines the advantages of simulation with regard to flexibility and the advantages of measurement with regard to the practical consideration of device and control specifics. The investigations were carried out using a micro-CHP unit, a ground source heat pump and an air source heat pump, but are also equally suitable for other types of generators in terms of methodology.

The results presented show that the choice of balance periods and system boundaries is of great importance. It is advantageous to evaluate the entire generation system and use representative days. Simulation studies indicate that suitable days can be selected from a weather data set using the $\mathrm{k}$-medoids clustering method. This results in a good prediction accuracy for a number of four days with at the same time low testing effort.

The results also demonstrate that the method can be used to take account of significant influencing variables on the efficiency of heat generators. For the individual typical days, the daily efficiency rates, especially for the heat pump systems, are strongly dependent on the respective average load factor. However, the days with increased heating energy expenditure (winter days) are decisive for the level of the annual utilisation rate or annual performance factor. Within a round robin test for the verification of the procedure, a good agreement could be achieved with regard to the determined energetic efficiencies.

Furthermore, the presented evaluation method is conceptually designed in such a way that it is basically possible to extend it to other types of generators such as hybrid systems. This has to be considered in further investigations. In addition, the method has a high potential for further development and improvement with regard to the mode of operation and control of generation systems.

\section{References}

1. K. Huchtemann, Supply Temperature Control Concepts in Heat Pump Heating Systems (Ph. D. thesis, RWTH Aachen University, Aachen, 2015)

2. DIN - German Institute for Standardization, DIN EN 14825 - Air conditioners, liquid chilling packages and heat pumps, with electrically driven compressors, for space heating and cooling - Testing and rating at part load conditions and calculation of seasonal performance (2016)

3. VDI - Association of German Engineers, VDI 4650 sheet 1, Calculation of the annual performance factor of heat pump systems - Electric heat pumps for space heating and domestic hot water heating (2016)

4. DIN - German Institute for Standardization, DIN EN 14511, Air conditioners, liquid chilling packages and heat pumps for space heating and cooling and process chillers, with electrically driven compressors (2018)

5. DIN - German Institute for Standardization, DIN 4709, Standard efficiency factor for micro-CHPappliances of nominal heat input not exceeding 70 $k W(2011)$

6. DIN - German Institute for Standardization, DIN EN 50465, Combined heat and power appliance of nominal heat input inferior or equal to $70 \mathrm{~kW}(2015)$

7. A. Perschk, Building and system simulation - a "Dresden model", Gesundheitsingenieur, 4 (2010)

8. S.A. Klein et al.: TRNSYS 14.2 A Transient System Simulation Programm (University of Wisconsin, Madison USA, 1996)

9. Modelica Association, Modelica. (URL https://modelica.org, 2018)

10. Dassault Systems, Dymola - multi-engineering modelling and simulation (http://www.3ds.com/ products/catia/portfolio/dymola, 2017)

11. Transsolar Energietechnik GmbH: TRNSYS 17: Transient System Simulation Tool, Ver. 17 (2013)

12. DIN - German Institute for Standardization, DIN EN 16147 Heat pumps with electrically driven Compressors, testing, performance measurement and equipment marking requirements for heating domestic hot water (2017)

13. H. Engel, Development of a procedure for dynamic evaluations of heat pump systems (RWTH Aachen, E.ON Energy Research Center, Master's Thesis, 2015)

14. J. Christoffer, T. Deutschländer, M. Webs, Test reference years of Germany for medium and extreme weather conditions TRY (Deutscher Wetterdienst, Offenbach, 2004) 


\section{Nomenclature}

\section{Abbreviations and subscripts}

el electric

end end energy

fl flow

$\mathrm{H} \quad$ heating

re return

th thermal

tot total

W water

ASHP air source heat pump

CHP combined heat and power

DHW domestic hot water

GSHP ground source heat pump

HiL Hardware-in-the-loop

VDI Association of german engineers

Symbols

a number of days in a cluster (-)

$c_{p} \quad$ specific heat capacity $(\mathrm{J} /(\mathrm{kg} \mathrm{K})$

CoP Coefficient of Performance (-)

$S E \quad$ Summed error square

$f \quad$ weighting factor (-)

$H_{i} \quad$ heating value $(\mathrm{J} / \mathrm{kg})$

$l \quad$ number of clusters or typical days (-)

$m$ number of weather sizes (-)

$n \quad$ number of data points per day (-)

$\dot{m} \quad$ mass flow rate $(\mathrm{kg} / \mathrm{s})$

$P \quad$ electric power (W)

$Q \quad$ thermal energy $(\mathrm{J})$

$\dot{Q}$ heat flow (W)

SCoP Seasonal coefficient of Performance (-)

$W \quad$ electric energy $(\mathrm{J})$

$\eta \quad$ utilization rate $(-)$

$\vartheta \quad$ temperature $\left({ }^{\circ} \mathrm{C}\right)$

$\mu \quad$ data point in cluster center

$\tau \quad$ time

$x \quad$ data point (weather size) 